\title{
THE LONG TERM INFLUENCE OF LOW-LEVEL SARIN EXPOSURE ON BEHAVIORAL AND NEUROPHYSIOLOGICAL FUNCTIONS IN RATS
}

\author{
Jiří Kassa, Marie Koupilová, Josef Herink, Josef Vachek
}

Purkyně Military Medical Academy in Hradec Králové: Department of Toxicology

\begin{abstract}
Summary: 1. Long term effects of low doses of highly toxic organophosphorus agent sarin on behavioral and neurophysiological functions were studied in rats exposed to sarin by inhalation. The toxic effects of sarin were monitored using a functional observational battery (FOB), an automatic measurement of motor activity and a test of excitability of central nervous system at 3,6 and 12 months following sarin exposure. 2. The results indicate that sarin at symptomatic as well as asymptomatic doses (level 2 and 3) is able to induce some neurotoxic effects (a decrease in activity and mobility, an alteration of gait, an increase in stereotyped behavior) including an increase in the excitability of central nervous system (an increase in convulsive activity following the administration of pentamethylenetetrazole) in rats at 3 months following inhalation exposure. Some sings of increased excitability were also observed in sarin-exposed rats following 6 or 12 months (an increase in exploratory activity, body temperature and a hindlimb grip strength at 6 months following exposure to sarin at asymptomatic doses, an increase in tail-pinch response at 12 months following exposure to sarin at symptomatic doses). 3. Therefore, nerve agents such as sarin seem to be harmful not only at high, clinically symptomatic doses but also at low, clinically asymptomatic doses because of long term manifestation of alteration of neurophysiological functions in sarin-exposed rats without disruption of cholinergic nervous system.
\end{abstract}

Key words: Sarin; Low level inhalation exposure; Long term effects; FOB; Excitability; Rat

\section{Introduction}

Many Persian Gulf War veterans have returned with an array of unexplained complaints including chronic fatigue, muscle and joint pain, gastrointestinal complaints, loss of concentration, forgetfulness, emotional changes, impotence, headaches and insomnia that defy diagnostic classification (17). Some researchers have concluded on the basis of structured interviews regarding exposures sustained in the Gulf that some cases of neuropsychologic impairment might have been due to exposures to chemical warfare agents and that some may be linked to pyridostigmine bromide, organophosphorus insecticides, the insect repellent DEET (N,N-diethyl-m-toluamide) and other pesticides $(5,6,7)$. Haley and his co-workers suggest that some cases of illness in Gulf War veterans may represent chronic neurotoxicity caused by low-dose exposure to chemical warfare agents because neurotoxic chemical warfare agents (nerve agents), notably sarin, had been released in certain areas of the Gulf during the war destruction of Iraqi ammunition bunkers (11). This is very important question that demands serious investigation because there are gaps of knowledge regarding the potential health consequences of exposure to low, asymptomatic concentrations of nerve agents.
Nerve agents, highly toxic organophosphorus compounds (OPs) pose potential neurotoxic threats to both military and civilian populations, as evidenced in recent terroristic attacks in Japan (16). OP toxicity results from the irreversible binding to and inactivation of acetylcholinesterase (AChE, EC 3.1.1.7), the enzyme that normally catalyzes the hydrolysis of acetylcholine (ACh) at neuromuscular junctions and other cholinergic synapses. Accumulation of $\mathrm{ACh}$ in the synapse causes repetitive firing, resulting ultimately in overstimulation of cholinergic system including convulsions, respiratory failure and/or death. Lipophilic OPs such as soman and sarin can readily cross the blood-brain barrier and lead to neuronal death $(13,22)$. Therefore, exposure to high doses of nerve agents can result in severe brain pathology (10).

Less is known about the possible chronic consequences of low-level, asymptomatic exposure to these agents. The available data argue against the existence of low-dose or delayed neurotoxicity in the absence of acute symptoms, but those data are sparse (14). Therefore, further research is needed to determine whether low-dose exposure to chemical warfare agents can cause chronic impairment of neurological functions. We have initiated a project using rats to find out whether nerve agent sarin will induce the alteration of neurophysiological functions following single 
or repeated low-level inhalation exposure. The purpose of this study is to provide a foundation to assess the risk of human populations that may be exposed to low levels of sarin.

\section{Material and methods}

Male albino SPF rats weighing 180-200g were purchased from Konárovice (Czech Republic). They were kept in an airconditioned room and allowed to access to standard food and tap water ad libitum. Food as well as water were sterilized before using. The rats were divided into groups of ten animals. Handling of the experimental animals were done under the supervision of the Animal Use and Care Committee of the Medical Faculty of Charles University and the Military Medical Academy in Hradec Králové (Czech Republic).

Rats were exposed to low-level sarin (obtained from Zemianské Kostolany, Slovak Republic) in the inhalation chamber for 60 minutes. Low levels of exposure to sarin were considered as those levels that result in minimal reduction of AChE with no observable clinical signs and symptoms. Three levels of low dose exposure can be described as:

- level 1 is an exposure that results in no clinical signs or symptoms and an erythrocyte AChE inhibiton of $<20 \%$ $(0.8 \mu \mathrm{g} / \mathrm{l})$,

- level 2 is an exposure that results in no clinical sings or symptoms but a moderate inhibition of erythrocyte AChE - about 20\% (1.25 $\mu \mathrm{g} / 1)$. This level was used for a single or repeated exposure (three times per week),

- level 3 is an exposure that results in mild clinical signs such a salivation and miosis without convulsions and an inhibition of erythrocyte AChE of $40-50 \%(2.5 \mu \mathrm{g} / 1)$.

The rats were monitored using a functional observatory battery (FOB), a non-invasive and relatively sensitive type of neurobiological examination including measurements of sensory, motor and autonomic nervous functions, and a test of excitability of the central nervous system (CNS) by the observation of a convulsive activity following i.p. administration of pentamethylenetetrazole (PTZ) at a convulsive dose $\left(30 \mathrm{mg} / \mathrm{kg}, \mathrm{ED}_{10}\right)$ at 3,6 or 12 months following exposure to sarin. The experimental rats were compared with the control animals exposed to the pure air.

The FOB consists of 42 measurements of sensory, motor and autonomic nervous functions $(3,20)$ (Tab. 1). The first evaluation was made when sarin-exposed or control rats were in the home cage. The observer evaluated each animal 's posture, palpebral closure and gait and the presence or absence of convulsions was noted. Each rat was then removed from the home cage and briefly held in the hand. The presence or absence of spontaneous vocalization, piloerection and other fur and skin abnormalities as well as the irritability were noted too. Lacrimation and salivation were also observed. Other signs such as exophthalmus, crustiness around the eyes or emaciation were recorded too. Then rats were placed on a flat surface which served as an open field. A timer was started for three minutes during which the frequency of rearing responses was recorded. At the same time, gait characteristics were noted and ranked, and activity, tremor, convulsions and abnormal posture were evaluated. At the end of the third minute, the number of fecal boluses and urine pools on the absorbent pad was registered. Then, a reflex testing that consists of recording each rat's response to the frontal approach of the blunt end of a pen, a touch of the pen to the posterior flank and an auditory clic stimulus, was used. The responsiveness to a pinch on the tail and the ability of pupils to constrict in response to light were then assessed. These measurements were followed by a test for the aerial righting reflex, then by the measurements of forelimb and hindlimb grip

Tab. 1: Functional Observational Battery (FOB).

\begin{tabular}{|c|c|c|c|c|}
\hline \multicolumn{5}{|c|}{ Summary of Measures in the Functional Observational Battery } \\
\hline \multicolumn{3}{|c|}{ Scored Values } & \multicolumn{2}{|c|}{ Values in Absolute Units } \\
\hline $\begin{array}{c}\text { Home-cage } \\
\text { and Handling Measures }\end{array}$ & $\begin{array}{c}\text { Open } \\
\text { Field } \\
\end{array}$ & Other Measures & $\begin{array}{c}\text { Reaction } \\
\text { on Stimulations } \\
\end{array}$ & $\begin{array}{c}\text { Other } \\
\text { Measures } \\
\end{array}$ \\
\hline Posture & Exploratory Activity & Pupil Response to Light & Approach Response & Landing Foot Splay $(\mathrm{cm})$ \\
\hline Catch Difficulty & Urination & Righting Reflex & Touch Response & Forelimb Grip Strength (kg) \\
\hline Ease of Handling & Defecation & $\begin{array}{l}\text { Fall from Vertical } \\
\text { Position }\end{array}$ & Click Response & $\begin{array}{c}\text { Hindlimb Grip } \\
\text { Strength }(\mathrm{kg})\end{array}$ \\
\hline Muscular tonus & $\begin{array}{c}\text { Clonic } \\
\text { Convulsions }\end{array}$ & $\begin{array}{c}\text { Damage } \\
\text { of Respiration }\end{array}$ & $\begin{array}{l}\text { Tail-pinch } \\
\text { Response }\end{array}$ & $\begin{array}{l}\text { Forelimb and Hindlimb } \\
\text { Grip Strength }(\mathrm{kg})\end{array}$ \\
\hline Lacrimation & Tremor & & & Body Weight $(\mathrm{g})$ \\
\hline Palpebral Closure & Tonic Convulsions & & & Rectal Temperature $\left({ }^{\circ} \mathrm{C}\right)$ \\
\hline Endo-Exophthalmus & Gait & & & Horizontal Activity \\
\hline Piloerection & Mobility & & & Vertical Activity \\
\hline Skin Abnormalities & Tensions & & & \\
\hline Salivation & Vocalizations & & & \\
\hline \multirow[t]{2}{*}{ Secretion } & Stereotypy & & & \\
\hline & Bizarre behavior & & & \\
\hline
\end{tabular}


strength, body weight, rectal temperature and finally hindlimb landing foot splay. The whole battery of tests required approximately 6-8 minutes per one rat.

Motor activity data were collected shortly after FOB testing, using an apparatus for testing a spontaneous motor activity of laboratory animals (constructed in Purkyně Military Medical Academy in Hradec Králové, Czech Republic). The animals were placed for a short period (10 minutes) in the measuring cage and their movement (total horizontal activity, stereotypical activity, rearing, jumping, scratching, total vertical activity) were recorded.

The excitability of CNS was tested by the observation of a convulsive responses following i.p. administration of a convulsive dose of PTZ. Occurence of abnormal signs, especially the features and intensity of convulsions, was evaluated according to a specially elaborated scale (Tab. 2) as described previously $(8,12)$. Following the administration of PTZ, animals were placed into the experimental cage and individually observed for the period of 30 minutes after

Tab. 2: The scale used for the determination of the abnormal signs following the administration of PTZ at a convulsive dose.

\begin{tabular}{|c|c|}
\hline SCORE & Description of behaviour observed \\
\hline 0 & Without changes noticeable \\
\hline 0.5 & $\begin{array}{l}\text { Restlessness, sniffing, increased } \\
\text { locomotion, rearing, scratching }\end{array}$ \\
\hline 1.0 & Isolated myoclonic jerks \\
\hline 2.0 & Atypical minimal paroxysms \\
\hline 3.0 & Fully developed minimal paroxysms \\
\hline 4.0 & $\begin{array}{c}\text { Major (generalized) paroxysms } \\
\text { without tonic phase }\end{array}$ \\
\hline 5.0 & Generalized complete major paroxysms \\
\hline
\end{tabular}

PTZ challenge. The animals were always assignated the highest score observed and the average score was calculated for all groups and sarin doses.

Statistical analyses were performed on a PC with BMDP program P7D: analysis of variance (ANOVA) and t-test with Bonfferi 's corrections. Statistical analysis of the convulsive performances following the administration of PTZ was evaluated by means of t-test, the level of significance was set at the $5 \%$ level.

\section{Results}

Sarin-exposed rats did not show any clinical signs of intoxication and their body weight did not differ from control values at 3,6 as well as 12 months following the inhalation exposure.

The results of the study related to the measurement of sarin-induced alteration of behavioral and neurophysiological functions at 3 months following low-level sarin inhalation exposure of rats are summarized in Tab. 3. The significant alteration of mobile activity and gait characterized by ataxia and the increase in stereotyped behavior $(\mathrm{p}<0.001)$ was observed in rats repeatedly exposed to sarin at level 2 or singly exposed to sarin at level 3 . These animals had awkward hindlimbs and their mobility was markedly diminished. In addition, the significant increase in excitability of CNS characterized by the higher incidence of small and big seizures and other convulsive performances following administration of PTZ was monitored in rats repeatedly exposed to sarin at level 2 ( $\mathrm{p}<0.05)$ (Fig. 1).

The results of the monitoring of sarin-induced toxic effects at 6 months following low-level sarin inhalation exposure of rats are summarized in Tab. 4. The significant

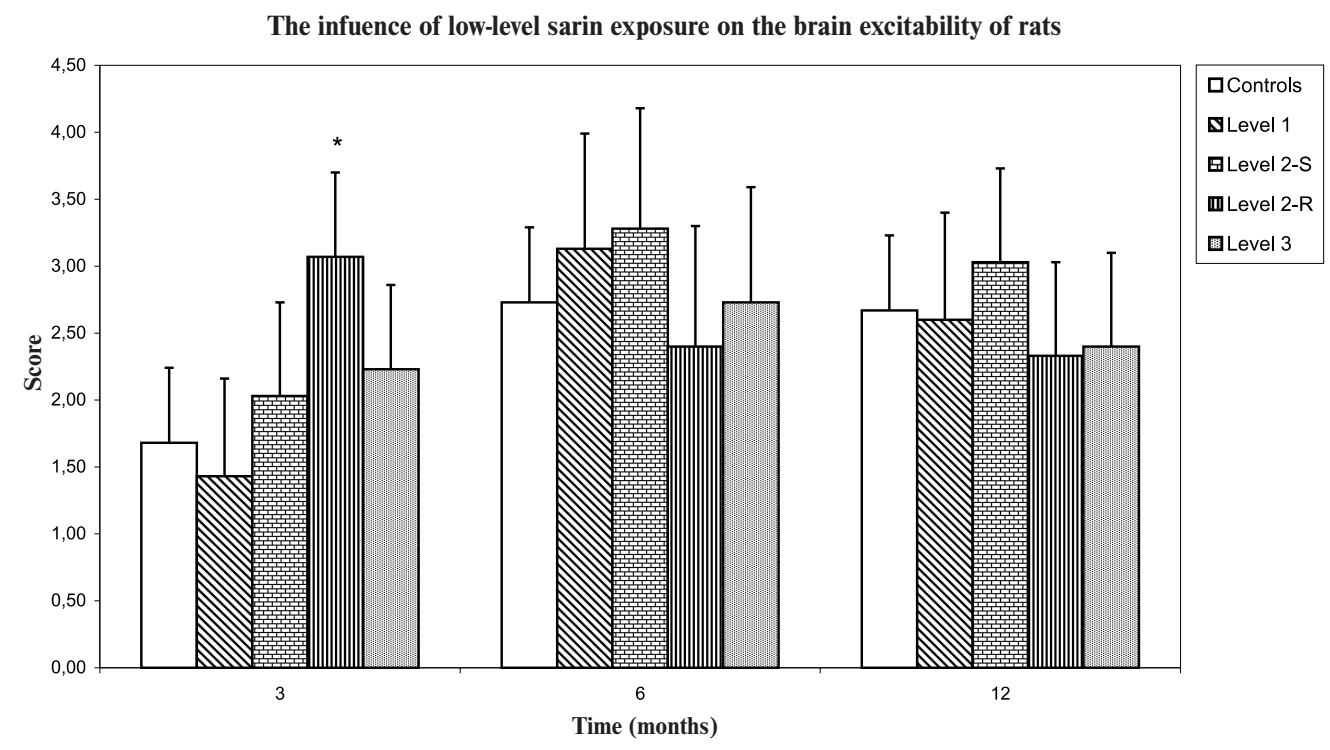

Fig. 1: The effect of administration of PTZ at the convulsive dose on the total score of abnormal signs in control and sarin-exposed rats at three, six and twelve months following exposure. Statistical significance: * $p<0.05$. 
signs of increased excitability - the increase in exploratory activity, observed in a home cage as well as an open field, rectal temperature and higher hindlimb grip strength $(\mathrm{p}<0.05)$ were demonstrated in rats exposed to sarin at level 1 or 2 . The increased horizontal and vertical activity and emotional lability were also monitored in the same rats but those changes were not significant. In addition, no significant changes in the seizure responses following the administration of the convulsive dose of PTZ were observed in sarin - exposed rats regardless of the level of sarin (Fig. 1).
The data related to the measurement of sarin-induced toxic effects at 12 months following low-level sarin inhalation exposure of rats are summarized in Tab. 5. Practically no marked neurotoxicity of sarin at all studied levels were observed at 12 months following the exposure with the exception of slightly increased horizontal as well as vertical motor activity and tail-pinch response in rats exposed to sarin at level 2 and 3. Similarly, no significant changes in the convulsive responses following the administration of the convulsive dose of PTZ were observed in sarin - exposed rats regardless of the level of sarin (Fig. 1).

Tab. 3: The values of sarin-induced neurotoxic markers measured by FOB at three months following sarin exposure (No 1-33, 40 - scored values, No 34-39, 41-42 values in absolute units). Statistical significance: ${ }^{*} \mathrm{p}<0.05,{ }^{* *} \mathrm{p}<0.01$, $* * * \mathrm{p}<0.001, \mathrm{X}-$ arithmetical mean of values.

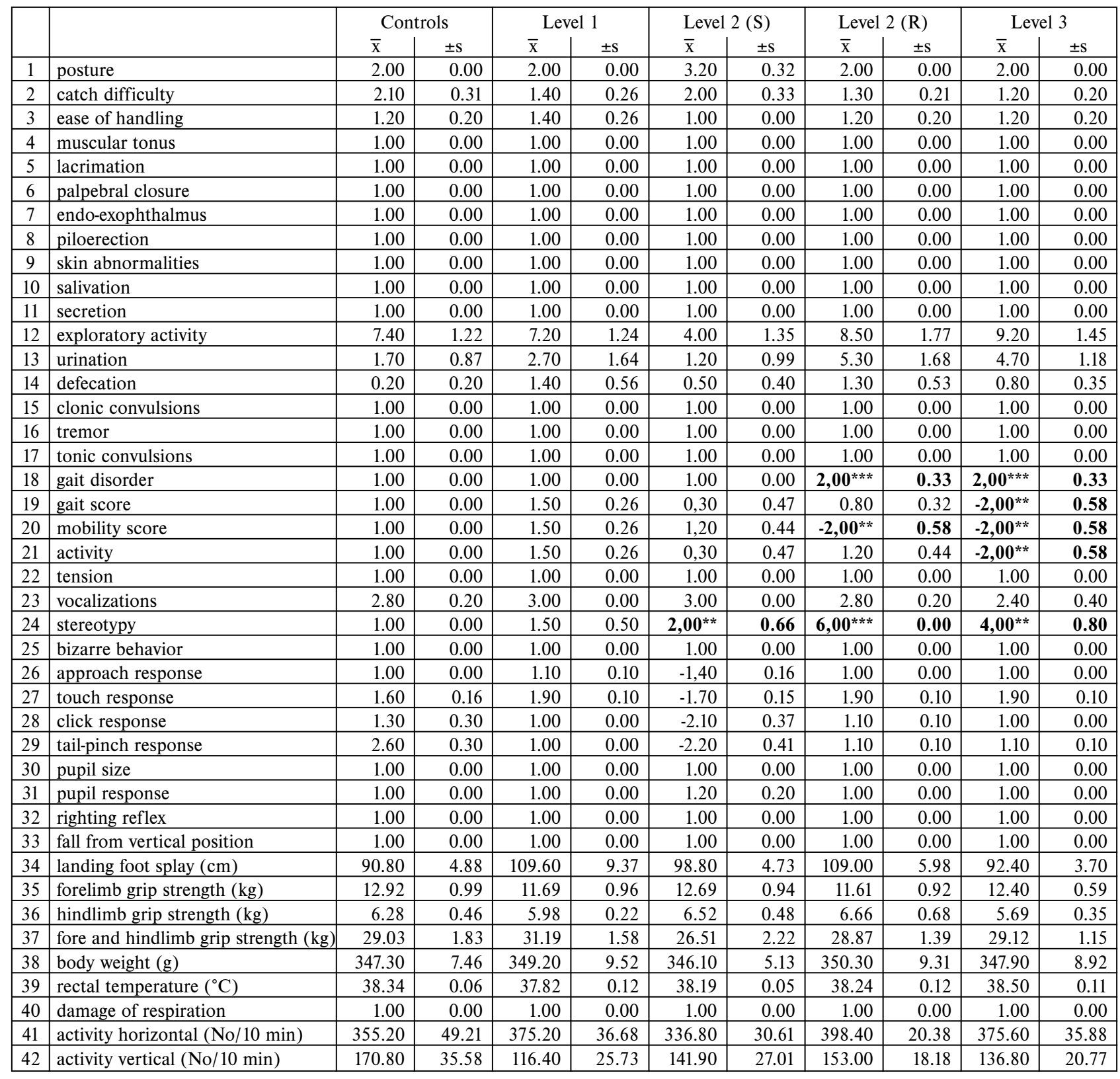


Tab. 4: The values of sarin-induced neurotoxic markers measured by FOB at six months following sarin exposure. For symbols - see Tab. 3.

\begin{tabular}{|c|c|c|c|c|c|c|c|c|c|c|c|}
\hline & & Cont & & Lev & & Level & & Level & $(\mathrm{R})$ & & \\
\hline & & $\overline{\mathrm{x}}$ & $\pm \mathrm{s}$ & $\overline{\mathrm{x}}$ & $\pm \mathrm{S}$ & $\overline{\mathrm{x}}$ & $\pm \mathrm{S}$ & $\overline{\mathrm{x}}$ & $\pm \mathrm{s}$ & $\overline{\mathrm{x}}$ & $\pm \mathrm{S}$ \\
\hline 1 & posture & 2.00 & 0.00 & $2,90^{* * *}$ & 0.30 & $2,90^{* * *}$ & 0.30 & 2.00 & 0.00 & 2.00 & 0.00 \\
\hline 2 & catch difficulty & 1.00 & 0.00 & 1.00 & 0.00 & 1.50 & 1.80 & 1.20 & 0.63 & 1.20 & 0.63 \\
\hline 3 & ease of handling & 1.00 & 0.00 & 1.00 & 0.00 & 1.30 & 0.94 & 1.00 & 0.00 & 1.20 & 0.60 \\
\hline 4 & muscular tonus & 1.00 & 0.00 & 1.00 & 0.00 & 1.00 & 0.00 & 1.00 & 0.00 & 1.00 & 0.00 \\
\hline 5 & lacrimation & 1.00 & 0.00 & 1.00 & 0.00 & 1.00 & 0.00 & 1.00 & 0.00 & 1.00 & 0.00 \\
\hline 6 & palpebral closure & 1.00 & 0.00 & 1.00 & 0.00 & 1.00 & 0.00 & 1.00 & 0.00 & 1.00 & 0.00 \\
\hline 7 & endo-exophthalmus & 1.00 & 0.00 & 1.00 & 0.00 & 1.00 & 0.00 & 1.00 & 0.00 & 1.00 & 0.00 \\
\hline 8 & piloerection & 1.00 & 0.00 & 1.00 & 0.00 & 1.00 & 0.00 & 1.00 & 0.00 & 1.00 & 0.00 \\
\hline 9 & skin abnormalities & 1.00 & 0.00 & 1.00 & 0.00 & 1.00 & 0.00 & 1.00 & 0.00 & 1.00 & 0.00 \\
\hline 10 & salivation & 1.00 & 0.00 & 1.00 & 0.00 & 1.00 & 0.00 & 1.00 & 0.00 & 1.00 & 0.00 \\
\hline 11 & secretion & 1.00 & 0.00 & 1.00 & 0.00 & 1.00 & 0.00 & 1.00 & 0.00 & 1.00 & 0.00 \\
\hline 12 & exploratory activity & 6.30 & 3.10 & $12,30^{*}$ & 4.70 & 7.20 & 4.40 & 5.80 & 4.60 & 3.30 & 2.00 \\
\hline 13 & urination & 2.90 & 3.70 & 1.20 & 1.90 & 4.50 & 4.30 & 4.50 & 4.30 & 4.20 & 6.00 \\
\hline 14 & defecation & 1.30 & 1.40 & 2.00 & 2.30 & 2.60 & 2.30 & 0.70 & 1.40 & 0.10 & 0.30 \\
\hline 15 & clonic convulsions & 1.00 & 0.00 & 1.00 & 0.00 & 1.00 & 0.00 & 1.00 & 0.00 & 1.00 & 0.00 \\
\hline 16 & tremor & 1.00 & 0.00 & 1.00 & 0.00 & 1.00 & 0.00 & 1.00 & 0.00 & 1.00 & 0.00 \\
\hline 17 & tonic convulsions & 1.00 & 0.00 & 1.00 & 0.00 & 1.00 & 0.00 & 1.00 & 0.00 & 1.00 & 0.00 \\
\hline 18 & gait disorder & 1.00 & 0.00 & 1.00 & 0.00 & 1.00 & 0.00 & 1.00 & 0.00 & 1.00 & 0.00 \\
\hline 19 & gait score & 1.00 & 0.00 & 1.00 & 0.00 & 1.00 & 0.00 & 1.00 & 0.00 & 1.00 & 0.00 \\
\hline 20 & mobility score & 1.00 & 0.00 & 1.00 & 0.00 & 1.00 & 0.00 & 1.00 & 0.00 & 1.00 & 0.00 \\
\hline 21 & \begin{tabular}{|l|} 
activity \\
\end{tabular} & 1.00 & 0.00 & 1.00 & 0.00 & 1.00 & 0.00 & 1.00 & 0.00 & 1.00 & 0.00 \\
\hline 22 & tension & 1.00 & 0.00 & 1.00 & 0.00 & 1.00 & 0.00 & 1.00 & 0.00 & 1.00 & 0.00 \\
\hline 23 & vocalizations & 1.00 & 0.00 & 1.00 & 0.00 & 1.00 & 0.00 & 1.00 & 0.00 & 1.00 & 0.00 \\
\hline 24 & stereotypy & 1.00 & 0.00 & 1.00 & 0.00 & 1.00 & 0.00 & 1.00 & 0.00 & 1.00 & 0.00 \\
\hline 25 & bizarre behavior & 1.00 & 0.00 & 1.00 & 0.00 & 1.00 & 0.00 & 1.00 & 0.00 & 1.00 & 0.00 \\
\hline 26 & approach response & 1.00 & 0.00 & 1.00 & 0.00 & 1,00 & 0.00 & 1.00 & 0.00 & 1.00 & 0.00 \\
\hline 27 & touch response & 2.00 & 0.00 & 2.00 & 0.00 & 2.00 & 0.00 & 1.90 & 0.30 & 1.90 & 0.30 \\
\hline 28 & click response & 1.00 & 0.00 & 1.00 & 0.00 & 1.30 & 0.90 & 1.00 & 0.00 & 1.40 & 0.90 \\
\hline 29 & \begin{tabular}{|l|} 
tail-pinch response \\
\end{tabular} & 1.00 & 0.00 & 1.00 & 0.00 & 1.00 & 0.00 & 1.40 & 0.40 & 0.90 & 0.30 \\
\hline 30 & pupil size & 1.00 & 0.00 & 1.00 & 0.0 & 1.00 & 0.1 & 1.00 & 0.0 & 1.00 & 0.00 \\
\hline 31 & pupil response & 1.00 & 0.00 & 1.20 & 0.4 & 1.00 & 0.0 & 1.00 & 0.00 & 1.00 & 0.00 \\
\hline 32 & righting reflex & 1.00 & 0.00 & 1.00 & 0.00 & 1.00 & 0.00 & 1.00 & 0.00 & 1.00 & 0.00 \\
\hline 33 & fall from vertical position & 1.00 & 0.00 & 1.00 & 0.00 & 1.00 & 0.00 & 1.00 & 0.00 & 1.00 & 0.00 \\
\hline 34 & landing foot splay $(\mathrm{cm})$ & 89.50 & 22.80 & 94.20 & 17.70 & 93.70 & 26.10 & 88.80 & 9.80 & 81.10 & 12.50 \\
\hline 35 & forelimb grip strength $(\mathrm{kg})$ & 13.60 & 3.90 & 12.80 & 3.70 & 13.30 & 2.50 & 14.70 & 3.50 & 13.50 & 1.80 \\
\hline 36 & hindlimb grip strength $(\mathrm{kg})$ & 4.80 & 1.10 & $6,50^{*}$ & 1.70 & $6,40^{*}$ & 0.70 & 5.80 & 1.00 & 4.20 & 0.70 \\
\hline 37 & fore and hindlimb grip strength $(\mathrm{kg})$ & 27.30 & 4.00 & 27.80 & 4.00 & 28.70 & 3.10 & 30.90 & 3.10 & 29.70 & 5.70 \\
\hline 38 & body weight $(\mathrm{g})$ & 388.20 & 40.50 & 375.10 & 44.50 & 376.50 & 19.20 & 398.60 & 28.70 & 390.40 & 43.40 \\
\hline 39 & rectal temperature $\left({ }^{\circ} \mathrm{C}\right)$ & 37.40 & 0.40 & $38,10^{*}$ & 0.30 & $38,10^{*}$ & 0.60 & 37.60 & 0.50 & 37.60 & 0.50 \\
\hline 40 & damage of respiration & 1.00 & 0.00 & 1.00 & 0.00 & 1.00 & 0.00 & 1.00 & 0.00 & 1.00 & 0.00 \\
\hline 41 & activity horizontal $(\mathrm{No} / 10 \mathrm{~min})$ & 257.10 & 107.60 & 380.50 & 94.50 & 318.90 & 72.10 & 353.10 & 136.20 & 281.70 & 109.80 \\
\hline 42 & activity vertical $(\mathrm{No} / 10 \mathrm{~min})$ & 58.10 & 54.70 & 108.50 & 59.60 & 81.60 & 32.10 & 100.30 & 65.30 & 72.50 & 59.10 \\
\hline
\end{tabular}


Tab. 5: The values of sarin-induced neurotoxic markers measured by FOB at twelve months following sarin exposure. For symbols - see Tab. 3.



\section{Discussion}

Sarin belongs to the most important and dangerous nerve agents for the wartime inhalation exposure because it is easy to manufacture and is the most volatile of the standard nerve agents. It has been reported to cause persistent neurotoxicity at clinically symptomatic doses $(9,23)$. Civilian employees working with or in the vicinity of sarin complained of a variety of symptoms including excessive dreaming, loss of libido, memory loss, irritability and trouble concentrating (2). Similarly, a slower syntatic reasoning, an increased reported forgetfulness and difficulties in thinking, an exposure-related increases in work-related tension, sleep disturbance, restlessness and nervousness have been documented among sheep farmers exposed to organophosphorus pesticides $(1,21)$. Sarin as well as soman have been also reported to decrease rearing and locomotor activity in the doses that significantly inhibit AChE activity in the blood without clinical symptoms due to the overstimulation the cholinergic nervous system (15). Dose-related decrease in spontaneous motor activity, fore and hindlimb grip strength and an increased excitability when handled 
were also observed a few hours following the administration of nerve agent soman at sublethal doses. These changes in behavior persisted up to 21 days following soman challenge (4). Chronic neurobehavioral and neurophysiological effects of acute sarin poisoning were also evaluated in several patients who were exposed to sarin poisoning in the Tokio subway incident in Japan. While the effects on psychiatric symptoms and fatigue appeared to result from posttraumatic stress disorder induced by exposure to sarin, the effects on psychomotor performance was caused directly by acute sarin poisoning (24).

In our study, similar long-term neurobehavioral and neurophysiological effects were monitored in rats exposed to low-level sarin three months following sarin inhalation. In addition, those effects were also found in rats exposed to sarin at doses that did not cause a significant inibition of AChE activity and a clinically manifested overstimulation of cholinergic nervous system. The findings correspond with earlier published data about neurological and neurophysiological outcomes detectable months or even years following the recovery from acute poisoning $(19,24)$ It means that probably other than cholinergic nervous system can be involved in nerve agent-induced long term signs of alteration of neurological and neurophysiological functions. It has been reported that there are protein targets present in brain which are known to be very sensitive to some anticholinesterases including nerve agents which may represent a target for low-level effects, either adverse or beneficial. However, the function of these protein targets are not yet known (18).

Although these findings are difficult to extrapolate directly to human low level exposures to nerve agents, they indicate that subtle neurophysiological and behavioral dysfunctions could also occur in humans at months following the inhalation exposure to non-convulsive symptomatic or even repeated inhalation exposure to asymptomatic level of sarin.

\section{Acknowledgements}

The authors would like to thank Mrs. E. Vodáková, Mrs. J. Bajgarová, Mrs. E. Reslová, Mrs. J. Petrová and Mrs. H. Antlová for their skilful technical assistance and to Mgr. V. Bláha for the statistical evaluation.

This study was supported by the grant of Ministry of Defence, No 66020397202.

\section{References}

1. Beach JR, Spurgeon A, Stephens R. Abnormalities on neurological examination among sheep farmers exposed to organophosphorus pesticides. Occup Environ Med 1996;53:520-6.
2. Burchfiel JL, Duffy FH. Organophosphate neurotoxicity: chronic effects of sarin on the electroencephalogram of monkeys and man. Neurobehav Toxicol Teratol 1982;4:767-78.

3. Frantik E, Hornychová M. Clustering of neurobehavioral measures of toxicity. Homeostasis 1995;36:19-24.

4. Haggerty GC, Kurtz PJ, Armstrong RD. Duration and intensity of behavioral change after sublethal exposure to soman in rats. Neurobehav Toxicol Teratol 1986;8:695-702.

5. Haley RW, Hom J, Roland PS. Evaluation of neurologic function in Gulf War veterans: a blinded case-control study. JAMA 1997;277:223-30.

6. Haley RW, Kurt TL. Self-reported exposure to neurotoxic chemical combinations in the Gulf War: a cross-sectional epidemiologic study. JAMA 1997;277:231-7.

7. Haley RW, Kurt TL, Hom J. Is there a Gulf War syndrome? - searching for syndromes by factor analysis of symptoms. JAMA 1997;277:215-22.

8. Herink J, Koupilová M, Hrdina V. Effects of tetrahydroaminoacridine (Tacrine) derivatives and physostigmine in convulsions induced by pentametylenetetrazol. Activ Nerv Sup 1989;31:303-5.

9. Husain K, Vijayaraghavan R, Pant SC, Raza SK, Pandey KS. Delayed neurotoxic effect of sarin in mice after repeated inhalation exposure. J Appl Toxicol 1993;13:143-5.

10. Kadar T, Shapira S, Cohen G, Sahar R, Alkalay D, Raveh L. Sarin-induced neuropathology in rats. Hum Exp Toxicol 1995;14:252-9.

11. Landrigan PJ. Illness in Gulf War veterans. JAMA 1997;277:259-61

12. Mareš $\mathrm{P}$, Marešová $\mathrm{D}$, Schickerová R. Effect of antiepileptic drugs on metrazol convulsions during ontogenesis in the rat. Physiol Bohemoslov 1981;30:113-21.

13. Marrs TC. Organophosphate poisoning. Pharmacol Ther 1993;58:51-66

14. Moore DH. Long term health effects of low dose exposure to nerve agent. ASA Newslett. 1998;98-2:20-3.

15. Nieminen SA, Lecklin A, Heikkinen O, Ylitalo P. Acute behavioural effects of organophosphates sarin and soman in rats. Pharmacol Toxicol 1997;67:36-40.

16. Ohtomi S, Takase M, Kumagai F. Sarin poisoning in Japan. A clinical experience in Japan Self Defense Force (JSDF) Central Hospital. Internal Rev Arm For Med Ser 1996;69:97-102.

17. Persian Gulf Veterans Coordinating Board. Unexplained illnesses among Desert Storm veterans: a search for causes. Treatment and cooperation. Arch Internal Med 1995; 155:262-8.

18. Ray DE. Chronic effects of low level exposure to anticholinesterases - a mechanistic review. Toxicol Lett 1998;102-103:527-33.

19. Savage EP, Keefe TJ, Mounce LM. Heaton RK, Lewis JA, Burcar PJ. Chronic neurological sequelae of acute organophosphate pesticide poisoning. Arch Environ Health 1998;43:38-45.

20. Slechta DA. Behavioral measures of neurotoxicity. Neurotoxicology 1989;10:27196.

21. Stephens R, Spurgeon A, Beach J, Calvert I, Berry H, Levy L, Harrington JM. An investigation into the possible chronic neuropsychological and neurological effects of occupational exposure to organophosphates in sheep farmers. HSE Contract Research Report 74/95, London UK, H.M.S.O. 1995.

22. Taylor, P. Anticholinesterase agents. In: Hardman, J.G. Limbird, L.E.(eds.): The Pharmacological Basis of Therapeutics, $9^{\text {th }}$ ed., New York: McGraw Hill, 1996:161-76

23. Wu S, Casida JE. Subacute neurotoxicity induced in mice by potent organophosphorus neuropathy target esterase inhibitors. Toxicol Appl Pharmacol 1996;139:195-202.

24. Yokoyama K, Araki S, Murata K et al. Chronic neurobehavioral and central and automatic nervous system effects of Tokio subway sarin poisoning. J Physiol Paris 1998;92:317-23.

Submitted September 2000.

Accepted January 2001. 